\title{
Samuel Rawet e Clarice Lispector no entre-lugar
}

\section{Samuel Rawet and Clarice Lispector in the between-place}

Stefania Chiarelli

Professora Adjunta de Literatura Brasileira da Universidade Federal

Fluminense (UFF). stefania.techima@uol.com.br

Thays Freitas de Almeida Pena

Doutoranda em Literatura Comparada pela Universidade Federal Fluminense (UFF). thaysfreitas@id.uff.br

(1) https://orcid.org/0000-0003-3747-144X

(1) https://orcid.org/0000-0002-3275-7580 Recebido em: 24/12/2018

Aceito para publicação em: 22/1/2019 


\section{Resumo}

Adotando como ponto de partida a concepção de Mikhail Bakhtin de que todo ato cultural vive nas fronteiras, este estudo busca explanar como a ideia das fronteiras culturais e seus limites elásticos é articulada nas obras Contos do imigrante (1956) e Laços de família (1960). Samuel Rawet e Clarice Lispector viveram no entre, nesse espaço intermediário e paradoxal, sendo assim, a indefinição de estar no mundo é o que há de mais íntimo para os autores, que se instalam no caminho do meio que a literatura propõe.

Palavras-chave: Fronteiras culturais. Entre-lugar. Contos. Samuel Rawet. Clarice Lispector.

\section{Abstract}

Taking as a starting point the conception of Mikhail Bakhtin that every cultural act lives on the frontiers, this study looks to explain how the idea of cultural boundaries and their elastic limits are articulated in the works Contos do imigrante (1956) and Laços de família (1960). Samuel Rawet and Clarice Lispector lived in the middle, in this intermediate and paradoxical space, and thus, the indefinition of being in the world is the most intimate for both, who settle in the middle way that literature proposes.

Keywords: Cultural boundaries. Between-place. Tales. Samuel Rawet. Clarice Lispector. 


\section{Literatura comparada e a construção de um espaço intersticial}

Samuel Rawet e Clarice Lispector possuem desagregações em comum: são estrangeiros naturalizados brasileiros e viveram sob o signo do desajuste. Acentuamos que a concepção de desagregação que utilizamos é a de cisão e de fragmentação. Eles instauraram a ruptura à tradição do conto brasileiro e inauguraram a própria forma de engendrar o texto e conceber a literatura. Diante da condição de seres estrangeiros naturalizados no Brasil, os autores vivem esta dupla vinculação. Essa já fora mencionada anteriormente por Tzvetan Todorov (1999, p. 19) ao falar de sua experiência como estrangeiro: "minha dupla vinculação produzia apenas um resultado: aos meus próprios olhos, ela surpreendia pela inautenticidade cada um de meus dois discursos, já que cada um podia apenas corresponder à metade do meu ser, ou então eu era um duplo". A dupla vinculação do estrangeiro é justamente pertencer tanto ao local de origem quanto ao de acolhida, e também não se sentir pertencente a nenhum dos dois espaços.

Samuel Urys Rawet nasceu no dia 23 de julho de 1929, na pequena cidade polonesa de Klimontov. Veio com a mãe e os irmãos para o Brasil com apenas sete anos de idade, aqui se naturalizando, em 1936. Com poucos recursos, instalaram-se na zona norte, no subúrbio do Rio de Janeiro, lugar que serviria de laboratório de experiências a serem recriadas em suas obras. Engenheiro calculista, ajudou a construir o Monumento aos Pracinhas, no Aterro do Flamengo, no Rio de Janeiro, além de trabalhar na equipe de Oscar Niemeyer na construção de Brasília. Samuel Rawet faleceu solitário e desconhecido do público, em Sobradinho, cidade satélite de Brasília, em 25 de agosto de 1984.

Clarice Lispector nasceu em 1920, na Ucrânia, numa pequena aldeia chamada Tchechelnik. Chegou ao Brasil com apenas dois meses de idade, em Maceió, para depois mudar-se para Recife e então para o Rio de Janeiro. Solicitou naturalização em Janeiro de 1943 para o seu casamento com o diplomata Maury Gurgel Valente. Segundo Nádia Gotlib (1995, p. 59), "é quando atualiza sua identidade, comunicando oficialmente a nova nacionalidade, a brasileira, paralelamente ao seu nome de casada, em setembro desse mesmo ano". Formou-se em Direito, contudo foi a carreira jornalística que perdurou em sua vida: trabalhou como redatora na Agência Nacional, na qual firmou amizades com futuros romancistas de renome. Morou no exterior para acompanhar o marido, onde escreveu parte de suas obras, porém a maioria de sua produção foi realizada em solo brasileiro, onde fora publicada. Faleceu no Rio de Janeiro, em 9 de dezembro de 1977. 
Rawet era de origem asquenaze, parte da população judaica do leste europeu falante do iídiche. É importante salientar os fatos que compõem sua identidade: o autor escreveu em português, sua segunda língua, sendo o ídiche sua matriz linguística. Saul Kirschbaum (2000, p. 41-42) destaca que "o uso do iídiche era rejeitado pelos judeus assimilados. Considerado um idioma inculto, encontrava-se intensamente vinculado aos judeus da Europa Oriental, indivíduos caracterizados por um modo de vida mais arcaico, em torno de práticas religiosas". Conforme Stefania Chiarelli (2007, p. 32), é o que leva o autor a "transitar entre três identificações culturais: polonesa, judaica e brasileira".

Já Clarice negava a estrangeiridade da língua: "A minha primeira língua foi o português. Se eu falo russo? Não, não, absolutamente..." (LISPECTOR apud WALDMAN, 2003, p. XXV). No entanto, seus pais eram de um povoado onde viviam os judeus do leste europeu, falantes do iídiche e não do russo. Para Berta Waldman (2003), por mais que o português possa ter sido seu primeiro idioma falado, sendo os seus pais falantes do iídiche, é possível que ela tenha sido iniciada em dois sistemas linguísticos simultaneamente. Waldman (2003, p. XXV) ainda revela: "um deles ela calou. Ela não se refere ao iídiche, embora esse fosse o idioma usado em sua casa". Esse silenciamento da língua surge como uma possível forma de desvincular-se da condição de estrangeira e um modo de consolidar-se brasileira.

"Indefinição, incoerência, atitude anticartesiana. Espanto, como elemento positivo, não diante do absurdo, mas diante da boçalidade maciça e da estupidez, esteja onde estiver." (RAWET apud GOMES, 1979, p. 168). É assim que Samuel Rawet define-se no mundo. Conhecido por ser arredio e desconfiado, "talvez por conhecer melhor - e se importar com isso - a hipocrisia humana, a baba na gravata do traidor" (BRASIL, 2008, p. 270). Toda a sua obra ficcional e ensaística é uma procura de identidade. Clarice Lispector também bebe nessa mesma fonte de imprecisão e afirma:

Se uma pessoa se perguntar durante meia hora a palavra 'eu', essa pessoa se esquece quem é. Outras podem enlouquecer. É mais seguro não fazer jamais perguntas - porque nunca se atinge o âmago de uma resposta. E porque a resposta traz em si uma outra pergunta. O que é que eu sou? (LISPECTOR apud BORELLI, 1981, p. 14).

A indefinição de estar no mundo é o que há de mais íntimo em Rawet e Clarice. A concepção de um ser uno e definível é oposta ao que vemos na obra dos autores. Para isto, é necessário lembrar que "todo ato cultural vive por essência nas fronteiras (BAKHTIN, 2014, p. 29). No domínio da cultura, não existe um território interior: ele 
situa-se inteiramente no "entre". Logo, torna-se relevante compreender que um "pensamento crítico é um pensamento fronteiriço, exerce-se não para além das fronteiras, mas na fronteira, isto é, mostra-se capaz de se situar nos espaços de articulação" (RIBEIRO; RAMALHO, 1999, p. 79). Deste modo, além de abarcar amplos domínios, essas fronteiras culturais muitas vezes são porosas, permeáveis e flexíveis, deslocam-se ou são deslocadas.

A interação que propomos entre as obras Contos do imigrante (1956) e Laços de família (1960) partilha da proposta de amalgamar fronteiras realizada pela literatura comparada em consonância com os estudos culturais. De modo que para Tania Carvalhal (1986, p. 82), a literatura comparada ambiciona "contribuir para elucidação de questões literárias que exijam perspectivas amplas. [...] Daí a necessidade de articular a investigação comparativista com o social, o político, o cultural, em suma, com a História num sentido abrangente". Isto posto, é possível apreender a importância dos estudos culturais para a nossa análise, visto que se torna primordial conceber como esse contexto cultural atua na obra de Rawet e Clarice.

Como consequência da compreensão de fronteira como um espaço possível de trânsito entre os locais de articulação, a literatura comparada se estabelece, não como um simples método de análise, ou tampouco limitada a uma disciplina, mas sim como diálogo, deslocamento de ideias. Há tempos a literatura comparada é objeto de estudo no Brasil: Eduardo Coutinho (2013) chama atenção para o fato de que mais importante do que responder perguntas sobre conceituação é antes primordial abrir novos caminhos através de seus estudos. Com isso, tornam-se possíveis múltiplos olhares oriundos desta reflexão, ao invés de limitar-se a conceituar e dessa maneira ir de encontro à concepção de fronteiras permeáveis e flexíveis apresentada pelos estudos culturais.

Em confronto com as literaturas nacionais, a literatura comparada fundamenta-se na compreensão de nação como algo em constante construção. Concepção essa já abordada por Ernest Renan (2006, p. 19): “a existência de uma nação é (perdoem-me esta metáfora) um plebiscito de todos os dias, como a existência do indivíduo é uma afirmação perpétua da vida". Diante disso, a ideia de um todo nacional permanente e íntegro torna-se indevida, visto que as fronteiras culturais possuem limites elásticos e permeáveis. Como resultado, as nações passam a ter caráter transitório e menos estável. O que resulta desses contatos culturais é o que Nestor Canclini (2015, p. XIX) define 
como hibridação: "processos socioculturais nos quais estruturas ou práticas discretas, que existiam de forma separada, se combinam para gerar novas estruturas, objetos e práticas". Desse modo, essas novas estruturas rompem com o ideal de pureza e fornecem uma multiplicidade de perspectivas culturais.

Ainda alicerçada na concepção de fronteiras porosas e do surgimento de novas práticas sociais, Nubia Hanciau (2012, p. 133) aborda o conceito de fronteira ambivalente ou bifronte apresentado por Sandra Pesavento: "Ela vê uma tendência a pensar fronteiras a partir da concepção que se ancora na territorialidade e se desdobra no político, nesse sentido a fronteira constitui-se em encerramento de um espaço". Pesavento avança o conceito para a nova temporalidade, a do mundo globalizado. Nele as fronteiras se apagam, figurando um "ir e vir" não apenas de lugar, sendo assim, compreendo que as fronteiras culturais transformam-se em amálgamas. Ou seja, fundem-se de tal maneira que possibilitam "- pelo contato e permeabilidade - o surgimento de algo novo, híbrido, um terceiro, que se insinua na situação de passagem". A partir dessa configuração de fronteiras amalgamadas é que o texto rawetiano e clariceano encontra seu lugar.

É nesse espaço aparentemente vazio que algo se instaura. Martin Heidegger (apud BHABHA, 2013, p. 19) conceitua que "uma fronteira não é o ponto onde algo termina, mas, como os gregos reconheceram, é sim o ponto a partir do qual algo começa a se fazer presente". Com efeito, a partir do surgimento desse algo novo, também chamado de entre-lugar, é que ocorre a reconfiguração dos limites entre centro e periferia, literatura e uma multiplicidade de vertentes culturais que circulam na contemporaneidade e ultrapassam fronteiras, fazendo do mundo uma formação desses entre-lugares. Nubia Hanciau afirma que lugar intervalar (Édouard Glissant), caminho do meio (Zilá Bernd), entre-lugar (Silviano Santiago), espaço intersticial (Homi Bhabha), são algumas variantes para denominar as zonas criadas pelos descentramentos, "quando da debilitação dos esquemas cristalizados de unidade, pureza e autenticidade, que vêm testemunhar a heterogeneidade das culturas nacionais no contexto das Américas e deslocar a única referência, atribuída à cultura europeia" (2012, p. 127).

Outrossim, é inadiável entender o conceito desses entre-espaços, e para tal fim Hanciau recapitula brevemente as concepções acerca do vocábulo. Édouard Glissant fala de lugares intervalares, identidades híbridas e negociação de identidades em culturas 
multifacetadas e abertas à relação com o outro, reconhecendo que todas as culturas são híbridas e que as misturas remontam às origens da história do homem; a escritura glissantiana propõe a formulação de uma nova ideologia saída da globalização. Para Zilá Bernd (apud HANCIAU, 2012, p. 129), "enraizamento e errância: duas faces da questão identitária". Dessa forma, seria necessário um "caminho do meio para superar a aporia fundamental encerrada pela questão identitária: afirmar-se e excluir o outro (ou seja, a afirmação das identidades passa pela negação das alteridades), ou desistir de se nomear e desaparecer" (HANCIAU, 2012, p. 129). Já Silviano Santiago no ensaio "O entre-lugar do discurso latino-americano", discute o lugar que ocupa o discurso literário do Brasil, e lembra que nossa difícil construção se dá em uma dialética rarefeita entre o ser e o outro, entre o ser explicado e o destruído, entre o ser constituído, mas não o ser explicado.

Ainda no mesmo ensaio, Santiago questiona o papel do intelectual e declara falida uma tendência no sistema universitário que são as pesquisas que conduzem ao estudo das fontes ou das influências. Ele afirma que tal discurso "reduz a criação dos artistas latino-americanos à condição de obra parasita, uma obra que se nutre de uma outra sem Ihe nunca acrescentar algo de próprio" (SANTIAGO, 2013, p. 20). Ademais, o autor chama atenção para a voz profética de Paul Valéry: "Nada mais original, nada mais intrínseco a si que se alimentar dos outros. É preciso, porém, digeri-los. O leão é feito de carneiro assimilado" (SANTIAGO, 2013, p. 21). Com isso, o autor situa o discurso literário latinoamericano no entre-lugar:

Entre o sacrifício e o jogo, entre a prisão e a transgressão, entre a submissão ao código e a agressão, entre a obediência e a rebelião, entre a assimilação e a expressão, - ali, nesse lugar aparentemente vazio, seu tempo e seu lugar de clandestinidade, ali, se realiza o ritual antropófago da literatura latino-americana (SANTIAGO, 2013, p. 30).

No que concerne as diversas definições de entre-lugar, Hanciau (2012, p. 137) explana que para Homi Bhabha a definição de terceiro espaço ou espaço intersticial parte de uma "noção linguística em que qualquer mensagem entre Sujeito e Objeto cria um lugar aberto a uma gama de possibilidades, que não seriam vislumbradas nem pelo emissor nem pelo receptor". No campo cultural, esta base teórica permite sair do binário, já que o terceiro espaço não pretende ser apenas um terceiro termo, mas um entre-lugar que o engloba e o ultrapassa. Bhabha (2013, p. 20) conclui que os entre-lugares fornecem o campo para "elaboração de estratégias de subjetivação que dão início a 
novos signos de identidade e a postos inovadores de colaboração e contestação no ato de definir a própria ideia de sociedade".

Rawet e Clarice viveram no entre, nesse espaço intermediário e paradoxal. Os autores são cindidos por identidades e culturas, e isto manifesta-se tanto na obra quanto na vida dos dois. Nelson Vieira (2008, p. 486) declara que os autores demonstram-nos que "o verdadeiro locus da cultura está no indivíduo". Por esse motivo, ver o sujeito como grupo ou pertencente a uma nação é também entender de que maneira essa identidade será constituída coletivamente. À vista disso, no intuito de construir uma identidade nacional pode emergir não raramente um impulso de reprimir as diferenças: "pode-se descobrir os outros em si mesmo, e perceber que não se é uma substância homogênea, radicalmente diferente de tudo o que não é si mesmo; eu é um outro. Mas cada um dos outros é um eu também, sujeito como eu" (TODOROV, 1999, p. 3). Em Rawet e Clarice, a diferença é constituinte da identidade descentrada do sujeito, é através dela que a alteridade é contextualizada e se faz presente em suas obras.

\section{Nas margens: narrativas que habitam o terceiro espaço}

Como em Rawet, a estrangeiridade pulsa na obra de Clarice Lispector. No conto "A menor mulher do mundo" temos a narrativa que se inicia "nas profundezas da África Equatorial", quando o explorador Marcel Prêtre "defrontou-se com uma mulher de quarenta e cinco centímetros, madura, negra, calada" (LISPECTOR, 1960, p. 81). Ele a categoriza como a menor mulher do mundo, grávida do menor ser humano do mundo. Rapidamente, o explorador informa à imprensa o achado e a notícia se espalha pelo mundo, famílias liam os jornais de domingo com a manchete e o retrato da "Pequena Flor", nome que fora dado a ela para sanar o anseio do explorador de classificá-la.

A menor mulher do mundo foi catalogada e nomeada a fim de conseguir identificá-la entre "as realidades reconhecíveis". A dominação inicia na necessidade do explorador de dar nome, de colher dados e por meio disso torná-la parte daquilo que ele entendia como possível. Contudo, Pequena Flor ainda ultrapassava o desejo de dominação de Marcel, pois ela "coçou-se onde uma pessoa não se coça" (LISPECTOR, 1960 , p. 83). Aquilo que foge ao entendimento ou o que não é normativo é taxado como estranho, exótico. O conceito de exotismo é abordado por Vitor Segalen que o define como esthétique du Divers, ou seja, a "estética do diverso" (MOURA, 2003, p. 25, tradução nossa), na qual o conceito se fundamenta na experiência da alteridade em seu 
sentido mais amplo, o sentido da diferença. Ele afirma: "o exostimo não se exerce somente nas diferenças de nações ou culturas, mas também em qualquer diferença que separa um objeto de um outro, um ser de um outro ser" (SEGALEN apud MOURA, 2003, p. 25, tradução nossa). 1

Já Jean-Marc Moura define que o exótico está na linguagem resultante do contato de culturas, a qual confere um grau único de exotismo: "[...] Mas à medida que as civilizações se aproximam umas das outras, torna-se possível confrontar mais claramente o que constitui sua irredutível singularidade, nisso que se baseia a sua realidade exótica" (MOURA, 2003, p. 42, tradução nossa). ${ }^{2}$ Diante dessa concepção de exotismo como a singularidade resultante da aproximação de povos, Pequena Flor, mesmo catalogada, era retratada como a figura exótica, marcada pela diferença, que causava estranhamento e incomodava Marcel Pretre, apesar do domínio que ele pensara ter realizado através da classificação.

A fotografia de Pequena Flor estava no jornal de domingo. O jornal do sétimo dia (do descanso, segundo a Bíblia), do dia da família, e mais ainda, "sua fotografia foi publicada no suplemento colorido dos jornais de domingo, onde coube em tamanho natural" (LISPECTOR, 1960, p. 83). Então os olhares varreram Pequena Flor. Uma mulher não a olhou uma segunda vez porque dava aflição. Outra sentiu "ternura pela pequenez da mulher africana". Em uma determinada família, Pequena Flor foi motivo de debate: a filha de treze anos queria saber o tamanho do nenenzinho dela, a mãe prontamente respondeu que seria "o menor bebê preto do mundo". Já até imaginava Pequena Flor servindo a mesa da família e argumenta que "se trata de uma coisa rara" (LISPECTOR, 1960, p. 86). A menor mulher do mundo causava estranhamento a todos, fora animalizada, estigmatizada, estereotipada e ainda assim, sorriu.

Marcel Prêtre não conseguia entender que "a própria coisa rara tinha coração”, que guardava “o segredo do próprio segredo: um filho mínimo” (LISPECTOR, 1960, p. 86).

\footnotetext{
1 Na obra Exotisme et lettres francophones, Jean-Marc Moura apresenta a concepção sobre "exotismo" segundo Vitor Segalen: "I'exostime ne s'exerce pas seulement sur les différences de nations ou de cultures, mais aussi sur toute différence qui sépare un objet d'un autre, un être d'un autre être" (SEGALEN apud MOURA, 2003, p. 25).

2 Jean-Marc Moura também expõe a sua própria definição para o termo exotismo: "Mais à mesure que les civilisations se raprochent les unes des autres, il devient possible de se confronter plus clairement à ce qui constitue leur irréductible singularité, à ce en quoi repose leur réalité exotique" (MOURA, 2003, p. 42).
} 
Não vendo alternativa para o que não atingia, "o explorador sentiu mal-estar". A menor mulher do mundo estava rindo, estava "gozando a vida". Giovanna Dealtry menciona que "se a notação científica recoloca o personagem no trilho da ordem, e, consequentemente, da posse sobre 'o outro', é o abismo do corpo diminuto, grávido, quente e que ri, o corpo restituído à existência, que irá lançar o explorador, momentaneamente, à vertigem" (2016, p. 238). Diante de todo o estranhamento do explorador, ela ria. Ria, pois não estava preocupada com sua fotografia no jornal, nem com os olhares e comentários que fizeram sobre ela. "Não ser devorado é o objetivo secreto de toda uma vida" (LISPECTOR, 1960, p. 87). Ria, pois ignorava que se chamava Pequena Flor, ignorava que fora nomeada. Ria, pois entendia que não fora devorada, por isso estava feliz.

Para o explorador restou o desconcerto. Marcel Prêtre estava atrapalhado, ainda sem compreender porque a menor mulher do mundo "piscava de amor, e riu quente, pequena, grávida, quente" (LISPECTOR, 1960, p. 87). A despeito de toda a tentativa do explorador em normatizá-la, a menor mulher do mundo continuava a viver em sua árvore, continuava grávida do menor ser humano do mundo, para ela "amor é não ser comido". Caterina Koltai (1998, p. 110) esclarece que "não há nada de mais estrangeiro para o sujeito que sua própria anterioridade. O modo como se lida com a própria estrangeiridade pesa na hora de definir o outro como estrangeiro". Por conseguinte, o explorador define a menor mulher do mundo a partir da ótica etnocêntrica, em que o outro só existe a partir do instante em que ele classifica, nomeia e divulga. Esse outro que aparece na figura da Pequena Flor que apenas ri de toda a "descoberta" de Marcel Prêtre.

Segundo Koltai, a maneira como o indivíduo lida com sua própria estrangeiridade refletirá na sua definição do que é estrangeiro. No conto de Clarice, a menor mulher do mundo fora taxada como estranha pela perspectiva do explorador, pois ele definiu como estranho aquilo que não era reconhecido por ele como normativo. Outrossim, a temática do estrangeiro atravessa a narrativa de Rawet de forma consubstancial, e no conto "A prece" está expressa mais diretamente. Na narrativa, Ida é imigrante e judia, que acabara de chegar na vizinhança. Em sua casa, ela vivia das memórias de sua família e da vida que havia ficado para trás: "filhos, já os tivera, marido também. De tudo, só o retrato ficou na parede. E ela. No rosto marcado de rugas, um sofrimento triturado. Esquecia. Morreram-Ihe todos com a guerra" (RAWET, 1956, p. 24). Conhecida pelo silêncio e 
estranheza, Ida era constantemente motivo de chacota de meninos que moravam em sua rua, além dos olhares ríspidos dos demais residentes.

As lembranças de Ida eram sua companhia e refúgio na solidão que a tomava. A língua era um problema, ela não dominava o idioma e esta era uma barreira instransponível que a ameaçava diariamente na convivência com seus vizinhos. Ao longo de toda a narrativa, os silêncios da protagonista são categóricos, "a palavra que falta" (RAWET, 1956, p. 22). Para o estrangeiro, o silêncio não é somente imposto, ele está em você: "recusa de dizer, sono preso a uma angústia que quer permanecer muda, propriedade privada de sua discrição orgulhosa e mortificada - luz cortante, esse silêncio. [...] Nada a dizer, nada é para ser dito, nada é dizível" (KRISTEVA, 1994, p. 24).

A voz de Ida só foi escutada uma única vez, quando a personagem tenta através de mímica e poucas palavras pedir fósforo emprestado à vizinha Genoveva, "que custou a compreender o desejo da estranha" (RAWET, 1956, p. 22). Em poucos minutos, os meninos começaram o escárnio, Brito liderava a zombaria imediatamente tratou de jogar pedras aos pés de Ida, e só cessaram quando Genoveva esbravejou e interveio pela protagonista. Julia Kristeva (1994, p. 23) afirma sobre o estrangeiro: "entre duas línguas, o seu elemento é o silêncio. [...] Quem o escuta? No máximo, toleram você. Aliás, você quer realmente falar?". Ida sentia-se estrangeira àquela vida que não era sua, "perdida, sem língua, sem voz" (RAWET, 1956, p. 24), reiteradamente humilhada por Brito e seus parceiros, além de estar solitária em um mundo que não a acolhia, o qual sentia que apenas a exauria.

Ida mantinha as fotografias e os rituais religiosos na tentativa de resgate de um passado que lhe traz alento. Na "primeira sexta-feira no casarão", há a urgência em reencenar o ritual do Shabbat, em que, através da prece, Ida buscaria o reencontro com os seus, com o seu passado. Chiarelli (2007, p. 140) esclarece que "a prece é o único veículo de expressão da individualidade da personagem, feita na própria língua e no espaço privado do quarto. É como uma saída desesperada frente aos inúmeros interditos que sofre". O simples desejo de Ida de continuar seus rituais religiosos torna-se mais uma marca da estrangeiridade para seus vizinhos. Eles iniciam um processo violento e cruel enquanto especulam o que estaria acontecendo na casa de Ida quando invadem sua casa e seu quarto. 
Após a irrupção, ocorre a constatação de que o fruto de tamanha desconfiança e desrespeito dos vizinhos era apenas Ida realizando sua prece, "parada, diante das velas, os olhos nas chamas não procurava por em ordem o pensamento" (RAWET, 1956, p. 28). Chiarelli (2007, p. 141) aponta que nem na solidão do próprio quarto Ida se sente à vontade para revisitar suas memórias: "Suscita demasiada curiosidade. É bicho estranho de outras terras, preferindo palavras que ameaçam pela impossibilidade de serem compreendidas". O total desconforto de Ida perante a situação vivida resulta dessa estranheza e animalização da personagem, cujo lar é cruelmente violado, e tem sua prece maculada, interrompida:

De dentro vinha uma sensação de rutura, de algo que se tinha perdido com a prece gritada. As quatro paredes caiadas de branco eram-lhe estranhas, e ao tentar dar término à oração as palavras sussurradas vinham-lhe mecânicas. Um estreitamento da garganta fê-la soltar com um soluço tudo que lhe boiava no interior. Sentiu-se oca. Os dedos magros se entrelaçaram e com os dois punhos fundidos esfregou a testa. Oca. Soprou as velas uma a uma, serena, calma. Sentada diante dos castiçais, os olhos de Ida miravam os tocos apagados, e seguindo a linha das gotas de cera, glóbulos amontoados em miniaturas estranhas, a cabeça tombou silenciosa na toalha branca. (RAWET, 1956, p. 28)

Ida sente-se agora "oca", já que foi violado o vínculo mais íntimo com suas memórias. A prece é o momento catártico de contato com tudo que lhe é mais precioso: a família, a religião, as lembranças, o lugar de pertencimento. A personagem permanece parada e calada, mesmo diante da barbárie que experienciara. Esse silêncio que inicia e finaliza o conto permeia as narrativas de Samuel Rawet e dialoga com o silenciamento das personagens de Clarice Lispector, como a Pequena Flor que apenas ri, ou ainda como a migrante nordestina Macabéa, protagonista da obra A hora da estrela (1977). A esse respeito, Chiarelli (2007, p. 144) afirma que aproximar Macabéa e Ida provoca questões, "como o fato de serem personagens cuja experiência se resume a uma parca passagem pela existência, e cuja trajetória de vida aponta para a inviabilidade de grandes efeitos". Impossível ignorar que se trata, no caso de Pequena Flor e de Ida, de personagens femininos silenciados em sua subjetividade: negar à primeira uma individualidade e impor-lhe o nome, ignorar a fé da segunda, atribuindo a ela a pesada carga do estereótipo. Os não-ditos aqui tem uma potente função: eles significam e encontram no texto formas de nomear a experiência da estrangeiridade. Nos autores, a "narração do indizível" é ponto crucial para uma chave de leitura profícua de seus contos.

Nos contos rawetianos e clariceanos são assinaladas a presença oblíqua (no caso de Clarice) ou mesmo aparente (em Rawet) da presença de culturas diferentes: judaica e 
brasileira. Essa dualidade fora apontada por Todorov (1999, p. 21) concernindo a impossibilidade do estrangeiro: "a palavra dupla revelava-se uma vez mais impossível e encontrava-me cindido em duas metades, uma tão irreal quanto a outra". A irrealidade de ser apenas uma metade deve-se ao fato de que para o estrangeiro é impensável escolher entre uma e outra referência cultural. Para poder ser no mundo, o estrangeiro aprende como viver nesse caminho do meio, no qual transita entre uma cultura e outra, em que as duas formam esse terceiro. É através desse novo caminho que Rawet e Clarice inauguram uma forma de conceber o texto, transfigurando a linguagem de tal maneira que ali, naquela prosa, os dois exprimem o indizível e suas impossibilidades.

\section{Referências}

BAKHTIN, Mikhail. Questões de literatura e estética: a teoria do romance. São Paulo: Hucitec, 2014.

BHABHA, Homi K. O local da cultura. Belo Horizonte: Editora UFMG, 2013.

BRASIL, Assis. "Samuel Rawet, um marco literário". In: SANTOS, Francisco Venceslau dos (org.). Samuel Rawet. fortuna crítica em jornais e revistas. Rio de Janeiro: Editora Caetés, 2008.

BORELLI, Olga. Clarice Lispector. esboço para um possível retrato. Rio de Janeiro: Nova Fronteira, 1981. 
CANCLINI, Néstor Garcia. Culturas Híbridas: Estratégias para entrar e sair da modernidade. São Paulo: USP, 2015.

CARVALHAL, Tania. Literatura comparada. São Paulo: Ática, 1986.

CHIARELLI, Stefania. Vidas em trânsito: as ficções de Samuel Rawet e Milton Hatoum. São Paulo: Annablume, 2007.

COUTINHO, Eduardo. Literatura Comparada - Reflexões. São Paulo: Annablume, 2013.

DEALTRY, Giovanna. "Alma-palavra: voz e pertencimento indígena em Habitante irreal, de Paulo Scott". In: OLIVEIRA NETO, Godofredo de; CHIARELLI, Stefania. Falando com estranhos: o estrangeiro e a literatura brasileira. Rio de Janeiro: 7Letras, 2016.

GOMES, Danilo. Escritores brasileiros ao vivo vol. 1. Belo Horizonte, Ed. Comunicação: Brasília, 1979.

GOTLIB, Nádia. Clarice: uma vida que se conta. São Paulo: Editora Ática, 1995.

HANCIAU, Nubia. "Entre-lugar". In: FIGUEIREDO, Eurídice (Org.). Conceitos de Literatura e Cultura. Niterói: EdUFF, 2012 ; Juiz de Fora: EdUFJF, 2012.

KIRSCHBAUM, Saul. Samuel Rawet, profeta da alteridade. Dissertação (Mestrado em Língua Hebraica, Literatura e Cultura Judaicas) - Faculdade de Filosofia, Letras e Ciências Humanas, Universidade de São Paulo, 2000.

KRISTEVA, Júlia. Estrangeiros para nós mesmos (Trad. Maria Carlota C. Gomes). Rio de Janeiro: Rocco, 1994.

LISPECTOR, Clarice. Laços de família. São Paulo: Livraria Francisco Alves, 1960.

KOLTAI, Caterina (Org.). O estrangeiro. São Paulo: Escuta, FAPESP, 1998.

MOURA, Jean-Marc. Exotisme et lettres francophones. Paris: PUF, 2003. 
RAWET, Samuel. Contos do imigrante. Rio de Janeiro: Livraria José Olympio Editora, 1956.

RENAN, Ernest. "O que é uma nação?" Conferência realizada na Universidade Sorbonne em 11 de março de 1882. Tradução de Glaydson José da Silva. Revista Aulas. Campinas, n. 1, v. 1, agosto de 2006 .

RIBEIRO, Antonio Sousa; RAMALHO, Maria Irene. "Dos estudos literários aos estudos culturais?". In: Revista Crítica de Ciências Sociais. Universidade de Coimbra: Faculdade de Letras e Centro de Estudos Sociais, vol. 52/53, Fevereiro 1999.

SAID, Edward. Reflexões sobre o exílio e outros ensaios (Trad. Pedro Maia Soares). São Paulo: Companhia das Letras, 2003.

SANTIAGO, Silviano. Ensaios antológicos de Silviano Santiago. São Paulo: Nova Alexandria, 2013.

TODOROV, Tzvetan. O homem desenraizado. Rio de Janeiro: Record, 1999.

VIEIRA, Nelson. "Ser judeu e escritor - três casos brasileiros". In: SANTOS, Francisco Venceslau dos (Org.). Samuel Rawet. fortuna crítica em jornais e revistas. Rio de Janeiro: Editora Caetés, 2008.

WALDMAN, Berta. Entre passos e rastros: presença judaica na literatura brasileira contemporânea. São Paulo: Perspectivas, 2003. 